Original Article

\title{
Respiratory Morbidities among Children in a Grass Root Level Hospital in Bangladesh.
} ${ }^{*}$ Habib RB ${ }^{1}$, Kabir ARML ${ }^{2}$, Rouf $\mathrm{MA}^{3}$, Ullah MSS ${ }^{4}$, Hossain $\mathrm{MN}^{5}$, Rahman $\mathrm{MN}^{6}$, Boyan RK${ }^{7}$, Hye $\mathrm{MA}^{8}$, Khan $\mathrm{MKA}^{9}$, Roy $\mathrm{S}^{10}$, Haque $\mathrm{MR}^{11}$, Jamil JI ${ }^{12}$

\begin{abstract}
Children mostly suffer from respiratory illnesses around the world. Situation is not different in Bangladesh as suggested by many studies on childhood illness. But most of these studies have been done in tertiary level hospitals located in urban areas and very few were done in rural setting. This study was conducted to estimate the frequency and to determine the pattern of respiratory morbidity among children and also to assess the impact of passive smoking on the magnitude of acute respiratory tract infections (ARI) among children. This was an observational study. It was carried out on 1002 children over a period of about 180 days, who attended the Tungipara
\end{abstract}

$1{ }^{*}$ Dr. Rahat Bin Habib, Research Assistant, Department of Pediatrics, Sir Salimullah Medical Collage and Mitford Hospital, Dhaka. Email- ssmcdmc@gmail.com

2. Dr. A.R.M. Luthful Kabir, Professor of Pediatrics, Ad-din Medical Collage Hospital, Dhaka

3. Dr. Md Abdur Rouf, Professor of Pediatrics, Sir Salimullah Medical Collage and Mitford Hospita, Dhaka

4. Dr. Md. Sk. Shahid Ullah, Professor and Head, Department of Microbiology, Ad-din Sakina Medical Collage, Joshore.

5. Dr. Md. Nazmul Hossain, Associate Professor, Department of Pediatrics, Institute of Child and Mother Helath (ICMH), Dhaka.

6. Dr. Md.Anisur Rahman, Assistant Professor, Department of Pediatrics, SSMC and Mitford Hospital, Dhaka.

7. Dr. Rushdul Karim Boyan, Associate Professor, Department of Pediatrics, Mymensing Medical Collage, Bangladesh.

8. Dr. Md. Abdul Hye, Assistant Professor, Department of Pediatrics, Joshore Medical Collage, Bangladesh.

9. Dr. Md. Kamrul Ahsan Khan, Assistant Professor (Neonatology), Sheikh Sayera Khatun Medical Collage, Gopalganj.

10. Dr. Sudipta Roy, Assistant Professor, Department of Pediatrics, Ad-din Women's Medical Collage and Hospital, Dhaka.

11. Dr. Mohammad Rezaul Haque, Associate Professor, Department of Pediatrics, Institute of Child and Mother Health (ICMH), Dhaka.

12. Dr. Joheb Imtiaz Jamil, Assistant Professor, Department of Pediatrics, Institute of Child and Mother Health (ICMH), Dhaka ${ }^{*}$ For correcpondence
Upazila Health Complex (UHC), Gopalganj, Bangladesh between January 2018 and June 2018. Data were collected through face to face interview, physical examination, relevant investigations and collected data in the questionnaire for respiratory illness and others then respiratory data were not collected. Out of 1002 children, more then half (54\%) were male and the age range was new born to 168 months. Among them upper respiratory tract infections (URTI) were $98.5 \%$ as against only $1.5 \%$ of lower respiratory tract infections (LRTI). In this study, 38\% fathers were smoker and no mother found as smoker. Families of $63 \%$ patients used smoke producing substances for cooking. Respiratory illness was more prevalent among the children whose fathers used to smoke tobacco $\chi^{2}$ (1) 380 P 0.01. As well as babies more vulnerable for respiratory morbidity where smoke producing fuel used for cooking $\chi^{2}$ (1) $170 P$ 0.01._Children suffered more from diseases affecting the respiratory system than diseases of other systems. Simple cough related illness was the most common URTI. Under 05 children suffered most. Respiratory illness was more common among those whose fathers smoked tobacco. Children were more vulnerable to respiratory morbidity, where smoke producing fuel used for cooking. There need multicentric study to observe the real picture of respiratory morbidity.

Keywords: Respiratory morbidity, Children, Tungipara.

\section{INTRODUCTION}

Acute respiratory infections are the commonest causes of death among children. 14-15 million under 5 children die in each year in the world due to multiple cause, among them 4 million deaths are due to acute respiratory infection (ARI) and two thirds of them are infants. Thus on an average one child dies due to ARI every eight seconds. World wide more than 90 percent deaths occur in developing or underdeveloped countries. ${ }^{1}$

It is estimated that there are 19 million children under 5 in Bangladesh. In a study in ICMH, Bangladesh, found that $67 \%$ under 5 children attending in different hospitals were due to respiratory disorder. Among the patients 48\% suffered from common cold, $21 \%$ bronchiolitis, $11.5 \%$ bronchopneumonia and $8 \%$ due to bronchial asthma.$^{2}$ 
In another study, to identify the magnitude of lower respiratory tract infections among under 5 children attending an upozilla hospital in Bangladesh found that out of 600 cases (63\% male and 33\% female), responsible doctors diagnosed 39\% pneumonia casses, $6 \%$ bronchiolitis cases and other than $55 \%$ other than respiratory diseases. On the contrary according to clinical criteria of the study, pneumonia was diagnosed in $22.5 \%$ cases, bronchiolitis was $38 \%$ and other respiratory diseases in $47 \%$ cases. Therefore, variation in diagnosis of respiratory diseases occurs from physician to physician. ${ }^{3}$

A large number of children are affected by various types of respiratory diseases in Bangladesh each year. Very few studies have addressed issue of children of rural areas in this regard. This study have been conducted to determine the pattern as well as to estimate the frequency and magnitude of respiratory disease burden of children attending a primary level health care facility in a rural area of Bangladesh and to ascertain the pattern of respiratory morbidity of children attending a grass root level hospital in Bangladesh.

\section{MATERIALS AND METHODS}

This was a descriptive type of cross sectional study in the Tungipara Upazilla Health Complex (UHC), Gopalganj, Bangladesh. Study duration was six months (from January 2018 to June 2018). Study population were children attending the Pediatrics OPD of UHC, Tungipara, Gopalganj. Sample size were 1002. Purposive sampling method was applied. Children attending pediatric OPD of Tungipara UHC were included after receiving consent from their guardian during the study period. Only respiratory morbidities were collected by face to face interview and then physical examination, relevant investigation had done. Variable was, sociodemographyage, sex, consanguinity, parents smoking habit, cooing fuel, parents education status, parents monthly income. Respiratory illness-URTI-Cough, common cold, cough-common cold, cough-common cold-fever, common cold-fever, cough-fever, nasal blocked and LRTI were Broncheolitis, Bronchopneumonia, RAD, Bronchial asthma. Data collection Instrument was structured questionnaire, was formed by all variables. It has multiple parts, Initial part, i) particulars of the patients ii) sociodemographic information $2^{\text {rd }}$ part was i) parents complaints on respiratory problems. $3^{\text {th }}$ part was i) physical examination a. General b. System wise. Study toolsstethoscope, torch light, tongue depressor, auroscope.

\section{Results}

Table-I: Sociodemography

\begin{tabular}{|l|l|c|}
\hline Variables & Category & $\begin{array}{c}\text { Frequency \& } \\
\text { Percent }\end{array}$ \\
\hline Religion & Muslim & $905(90)$ \\
Hindu & $97(10)$ \\
\hline Sex & Male & $538(58)$ \\
& Female & $464(46)$ \\
\hline Age & Upto 01 month & $64(06)$ \\
& Upto 06 months & $247(24.5)$ \\
& 07 to 12 months & $175(17.5)$ \\
& 13 to 60 months & $466(46.5)$ \\
& 60 to 120 months & $110(11)$ \\
& 121 to 168 months & $04(0.5)$ \\
\hline Consanguinity & & $73(07)$ \\
Condition of living house & Tin shed & $830(83)$ \\
& Semi-paka & $55(5.5)$ \\
& Building & $117(11.5)$ \\
\hline
\end{tabular}

Table-II: System wise illness

\begin{tabular}{|l|c|c|}
\hline & Frequency & Percent \\
\hline Respiratory system & 489 & 49 \\
\hline GIT & 186 & 18.5 \\
\hline Skin & 166 & 16.5 \\
\hline Eye & 12 & 01 \\
\hline Urinary & 6 & 0.5 \\
\hline ENT & 5 & 0.5 \\
\hline CNS & 4 & 0.5 \\
\hline Others & 23 & 2.5 \\
\hline & 1002 & 100 \\
\hline
\end{tabular}

Near to half (49\%) children were suffered from respiratory illness and all others systemic illness were combined 51\%

Table-III: Complaint by parents on respiratory system

\begin{tabular}{|l|c|c|}
\hline & Frequency & Percent \\
\hline Only cold-cough & 358 & 73 \\
\hline Cough-cold with fever $<7$ days & 54 & 11 \\
\hline Cough-cold with fever $>7$ days & 29 & 06 \\
\hline Cold-cough, loose motion with fever & 07 & 1.5 \\
\hline Respiratory distress & 36 & 07 \\
\hline & 485 & 100 \\
\hline
\end{tabular}


In this study near to three quarter were suffered from only cough-cold and almost all (98.50\%) were suffered from cough related illness.

Table- IV: Father's tobacco habit

\begin{tabular}{|l|c|c|}
\hline & Frequency & Percent \\
\hline Smoker & 362 & 36 \\
\hline Smoke + Chewable tobacco & 17 & 02 \\
\hline Chewable tobacco & 49 & 05 \\
\hline No habit & 548 & 55 \\
\hline Others & 26 & 03 \\
\hline & 1002 & 100 \\
\hline
\end{tabular}

In this study $38 \%$ fathers were smoker and no mother found as smoker.

Table-V: Cooking fuel

\begin{tabular}{|l|c|c|}
\hline & Frequency & Percent \\
\hline Smoke producing fuel & 630 & 63 \\
\hline Cylinder gas & 200 & 20 \\
\hline Others & 172 & 17 \\
\hline & 1002 & 100 \\
\hline
\end{tabular}

There $63 \%$ cooked by smoke producing substances.

Table-VI: Non Parametric analysis

\begin{tabular}{|l|ll|}
\hline \multicolumn{1}{|c|}{ Chi square tests } & Result \\
\hline $\begin{array}{l}\text { Respiratory illness with father's } \\
\text { tobacco habit }\end{array}$ & $\chi^{2}$ (1) 380 & P 0.01 \\
\hline $\begin{array}{l}\text { Respiratory illness with smoke } \\
\text { producing cooking fuel }\end{array}$ & $\chi^{2}$ (1) 170 & P 0.01 \\
\hline
\end{tabular}

Their respiratory illness was more whose fathers used to smoke tobacco. As wall as babies more vulnerable for respiratory morbidity, where used smoke producing cooking fuel.

\section{DISCUSSION}

In this observational study, out of 1002 children, most were male and age range from new born to 168 months old. Diseases of the respiratory system topped the list (49\%). Upper respiratory tract illnesses (URTI) were $98.5 \%$ as against only $1.5 \%$ of lower respiratory tract illness (LRTI). This half of RTI affected by various types of respiratory tract illnesses (Table-3), which was in concordance with findings of a birth cohort study, in which respiratory illnesses contributed to more than $50 \%$ of the total disease burden. ${ }^{4} \mathrm{~A}$ higher burden $62 \%$ of respiratory illnesses has also been reported by longitudinal studies conducted among underprivileged children. ${ }^{5}$ So even in rural Bangladesh sickness pattern among children shows little variation. Upper respiratory tract is in immediate contact with the environment pollutants. Children specially the very young ones are more vulnerable to URTI.

Out of the total 489 cases of respiratory illness, 98.5\% suffered from upper respiratory tract diseases and of which three quarter of them suffered from cough-cold (Table-3). Another study, revealed that proportion of ARI was 55\% of all types of morbidities where $81 \%$ babies suffered by cough and cold . ${ }^{6}$

But the opposite was also found in another study in Bangladesh, where it was $35 \%$, this could be due to variation in time and place.?

In this study $38 \%$ of fathers were smoker. So it appears that passive smoking played an important role in causing sickness among children ( $\chi^{2} 380$ P 0.01) (Table-4,6). Use of smoke producing substances for cooking by households was also a significant contributor to the disease burden $\left(\chi^{2}\right.$ 170 P 0.01) (Table-6). In this study it was found that $63 \%$ of families used smoked producing substances for cooking (Table-5).

\section{CONCLUSIONS}

Children suffered more from diseases affecting the respiratory system than diseases of other systems. Simple cough related illness was the most common URTI. Under 05 children suffered most. Respiratory illness was more common among those whose fathers smoked tobacco. Children were more vulnerable to respiratory morbidity, where smoke producing fuel used for cooking. There need multicentric study to discover the real picture of respiratory morbidity.

\section{REFERENCES}

1. Kabir L.ARM et al, Management of Broncheolitis without antibiotics: A Multicentere Randomized Control Trial in Bangladesh, Acta Publication 2009; 98 (10): 1593-1599.

2. Jasimuddin $\mathrm{M}$ et al, Broncheolitis: An update. ICMH Journal 2011; 2 (1): 33-41 
3. Rezaul $\mathrm{H}$ et al, Management of the respiratory disorders in under five children attending the upazila hospitals of Bangladesh, ICMH Journal 2013; 4 (1): 19-25.

4. Pullan CR, Toms GL, Martin AJ, Gardner PS, Webb JKG, Appleton DR. Breast-feeding and respiratory syncytial virus infection. Br Med J. 1980; 281: 1034-36

5. Lapillonne A, Regnault A, Gournay V, et al. Development of a questionnaire to assess the impact on parents of their infant's bronchiolitis hospitalization. BMC Health Serv Res 2013;13:272.

6. Sazawal S, Black RE. Meta-analysis of intervention trials on case-management of pneumonia in community settings. Lancet 1992; 340: 528-33

7. Monto AS, Ullman BM. Acute respiratory illness in an American community; the Tecumseh study. J Am Med Ass 1974; 227: 164-9. 